\title{
Role of interleukin 6 in liver cell regeneration after hemi-hepatectomy, correlation with liver enzymes and flow cytometric study
}

\author{
Thamer Hadi Al-Ghamdi', Ihab Shafek Atta², Mohamed El-Refaei ${ }^{1}$ \\ ${ }^{1}$ College of Medicine, Al Baha University, Alaqiq, Saudi Arabia \\ 2Faculty of Medicine, Al-Azhar University, Assuit, Egypt
}

\begin{abstract}
Aim of the study: Liver regeneration after hemi-hepatectomy may be affected by several growth factors and cytokines. The aim is to evaluate the importance of interleukin 6 (IL-6) in the induction of liver cell regeneration and find correlations with other parameters such as liver enzymes, and DNA analysis by flow cytometric studies.

Material and methods: 80 adult male Sprague-Dawley rats were obtained and divided into two equal groups ( $n=40$ rats) to undergo $70 \%$ partial hepatectomy: group 1 - untreated (control) group; 40 rats not treated; and group 2 - treated group, 40 rats treated with IL-6 $35 \mu \mathrm{g} / 100 \mathrm{gm}$ body weight according to a lethality study for a period of 4 days, then hepatic resection was carried out according to the steps of Higgins and Anderson. Assessment of liver enzymes and bilirubin level was done. Flow cytometric study was done using a flow cytometer (FACSCalibur; Becton Dickinson) and DNA content was estimated with CellQuest software (Becton Dickinson).

Results: The levels of alanine aminotransferase (ALT), aspartate aminotransferase (AST) and alkaline phosphatase (ALP) were significantly higher in the untreated group of rats with liver resection. A higher value of bilirubin was observed in the treated group. Rat weight at sacrification was significantly lower in the group of rats treated with IL- 6 than those without treatment, $p<0.001$. Liver weight at sacrification was significantly higher in the group of rats treated with IL-6 $(p<0.001)$. The percentage of apoptotic cells with hypodiploid DNA content was determined from DNA histograms. Untreated rat resected liver showed a peak pattern that represented liver damage with high damage of $73.4 \%$.

Conclusions: Interleukin 6 is of value in induction of liver cell regeneration after seventy percent hemi-hepatectomy as evident by increased liver cell mass, liver enzymes and flow cytometric analysis.
\end{abstract}

Key words: flow cytometry, hepatocytes, interleukin 6, liver regeneration.

Address for correspondence

Dr. Thamer Hadi Al-Ghamdi, Al Baha University, College of Medicine, Albaha Campus University, 1988, Alaqiq, Saudi Arabia, e-mail: thaker@bu.edu.sa

\section{Introduction}

Following Fausto and Riehle [1], three subpopulations of hepatocytes are found: quiescent cells, primed cells, and replicating cells. In a healthy adult liver, approximately $0.005 \%$ of hepatocytes enter the cell cycle [2]. The rest are quiescent, in the G0 state. Following a partial hepatectomy, hepatocytes come into the cell cycle by shifting to the G1 phase and by the effect of growth factors the cells progress to the G1/S restriction point then to mitosis. Conversely, cells in G1 phase which have not attained the restriction point are able to revisit the quiescence in the state of deficiency of growth factors [3].

In the primary phase of liver regeneration, several inductions of early genes such as c-fos and c-jun occur [4]. These genes are controlled by the umbrella of cytokines and tumor necrosis factor (TNF) [5-7], and their function is to shift the liver cells to the G1 phase. TNF connects to its receptor found on the surface of Kupffer 
cells, and activates the transcription nuclear factor that results in elevation of interleukin 6 (IL-6) production. IL-6 attaches to its specific receptor on liver cells and interacts with gp130, resulting in activation of Janus kinase (JAK), which in turn phosphorylates the signal transducer and activator of transcription 3 (STAT3) [8].

The extracellular matrix (ECM) plays a significant role in regulating hepatocyte regeneration [9]. Following partial hepatectomy, degradation of the ECM by matrix metalloproteinases (MMP) occurs, under the effect of cytokines and TNF [10]. Reproduction of the ECM occurs again by nonparenchymal cells. The ECM has the capability to adhere to the growth factors, avoiding their activation, resulting in inhibition of cell proliferation by this indirect mechanism [11].

It is well recognized that mice lacking IL- 6 show regeneration of their livers more gradually than normal animals after injuries. In addition, binding stat-3 sites are also reduced in a concomitant association [12, 13]. It has been reported that TNF- $\alpha$ may motivate transforming growth factor $\alpha$ (TGF- $\alpha$ ) expression, resulting in binding of the epidermal growth factor receptors in liver cells, leading to their improved proliferative activity [14]. These results highlight the complicated systems that are involved in hepatic regeneration and repair.

Ren et al. [15] postulate that interleukin 22 (IL-22) and IL- 6 induced liver regeneration have a close relation to TGF- $a$ because IL-22 blockade in a Ren model resulted in lowered levels of hepatic TGF- $\alpha$. Other investigations have reported that IL- 6 gene expression was regulated by IL-22 $[16,17]$. It has been shown that IL-6 was elevated in both liver and serum after administration of IL-22 to mice. These results suggest that IL- 6 proliferative effects are interrelated with those of IL-22 and TGF- $\alpha$.

In the liver, stat- 3 is principally activated by IL- 6 and IL-22 plays a significant role in the acute-phase response and also possibly in the promotion of liver regeneration $[18,19]$. Assessment of the signaling pathway events after IL- 6 and IL-22 administration in the background of partial hepatectomy confirmed amplification of stat-3 activation [20-23].

The aim of the study was to assess the rate of liver regeneration after treatment with IL-6 in rats subjected to seventy percent partial hepatectomy; in addition to study the correlation between liver enzymes and the rate of regeneration; and finally, to analyze the DNA in regenerating cells by flow cytometric study.

\section{Material and methods}

\section{Animals}

80 adult male Sprague-Dawley rats weighing about 200-230 g were obtained from the animal residence for scientific studies, King Abdulaziz University (Jeddah, Kingdom of Saudi Arabia). The animals were housed in a pathogen-free environment in the animal residence of the Faculty of Medicine, Albaha University, Kingdom of Saudi Arabia, in a 12-h light-dark cycle with meals and water obtainable ad libitum. 70\% partial hepatectomy (PHx) was performed on 40 rats. All animal experiments were performed according to the Guide for the Care and Use of Laboratory Animals published by the National Institutes of Health, USA. All surgical procedures were performed under inhalation anaesthesia.

\section{Interleukin 6 lethality study on rats}

The male rats were brought and randomly distributed in several groups of 5 rats each. They were treated with different doses (20-80 $\mu \mathrm{g} / 100 \mathrm{~g})$ of IL- 6 . The number of surviving rats was recorded daily. This process was continued for 30 days. The rats were subjected to experiments in accordance with ethical standards [24].

\section{Experimental design}

Eighty male rats were divided into two equal groups ( $n=40$ rats) for $70 \%$ partial hepatectomy: group 1 control group, 40 rats not treated; and group 2 - treated group, 40 rats treated with IL-6, $35 \mu \mathrm{g} / 100 \mathrm{~g}$ body weight according to the lethality study. The treated group was given IL-6, $35 \mu \mathrm{g} / 100 \mathrm{~g}$ body weight intravenously daily for a period of 4 days. The rat treatment period was 4 days only. The different groups were under observation for the same period. Concerning 30 days, it was only for lethality and dose selection. We observed that the high dose of IL- 6 causes toxicity and we consider and suggest that it may be due to the reverse action of cytokine and the selection was done according to a dose-dependent curve. In the fourth day, the sacrifications were done in the fourth day of IL- 6 tratment and after 18 hours following the last dose.

\section{Surgical procedures}

Hepatic resection was carried out according to the steps of Higgins and Anderson [25]. The rats were anesthetized using buprenorphine $(0.05 \mathrm{mg} / \mathrm{kg})$, intramuscular acepromazine $(0.8 \mathrm{mg} / \mathrm{kg})$, and ketamine (40 mg/kg) followed by a midline laparotomy.

Following opening the upper abdomen, the liver was exposed, the resecting lobe was smoothly lifted whereas a 3-0 silk suture tie was sited below it and situated in proximity to the origin of the lobe. Over the top of the lobe, the two approximated ends of the suture were closely tied at its root close to the inferior vena cava. Three knots were tied and the tied lobe was 
dissected just distal to the suture using dissecting scissors. Approximation of the abdominal wall was done using a 3-0 polyglactin suture. Finally, closure of the skin with polyamide suture was done.

Serum samples were obtained on post-operative days 4 for liver function tests (LFTs). At sacrifice, the livers were weighed and prepared for histological analysis.

\section{Biochemical analysis}

Routine analysis was performed at the Department of Clinical Biochemistry, Albaha University Faculty of Medicine, on the day of euthanization. Blood was sampled from the heart at sacrifice, processed and stored at $-80^{\circ} \mathrm{C}$ until analysis. Alanine aminotransferase (ALT), aspartate aminotransferase (AST), alkaline phosphatase (ALP) and bilirubin (BUL) levels were measured on a Cobas 6000 (Roche Diagnostics, Basel, Switzerland), using a routine protocol.

\section{Assessment of hepatic regeneration}

Hepatic regeneration ratio: The hepatic regeneration ratio (HRR) was calculated for each animal, and defined as [26]:

Table 1. Comparison of liver enzymes between compared groups of rats

\begin{tabular}{|c|c|c|}
\hline \multirow[t]{2}{*}{ Enzyme assay } & \multicolumn{2}{|c|}{ Rat groups } \\
\hline & $\begin{array}{c}\text { Control group } \\
\text { (no treatment) } \\
n=40\end{array}$ & $\begin{array}{c}\text { Resected and } \\
\text { treated group } \\
\quad n=40\end{array}$ \\
\hline \multicolumn{3}{|l|}{ ALT (IU/I) } \\
\hline Median & 244.15 & 180.7 \\
\hline IQR & $239-254.6$ & $174.2-188.8$ \\
\hline Mean rank & 50.5 & 30.5 \\
\hline$p$-value* & \multicolumn{2}{|c|}{$<0.001$} \\
\hline \multicolumn{3}{|l|}{ AST (IU/I) } \\
\hline Median & 118.3 & 68.8 \\
\hline IQR & $108.1-130.3$ & $65.1-76.3$ \\
\hline Mean rank & 50.4 & 30.55 \\
\hline$p$-value* & \multicolumn{2}{|c|}{$<0.001$} \\
\hline \multicolumn{3}{|l|}{$\operatorname{ALP}(I \mathrm{I} / \mathrm{I})$} \\
\hline Median & 185 & 113 \\
\hline $\mathrm{IQR}$ & 179-190.6 & 104.3-127.1 \\
\hline Mean rank & 50.5 & 30.5 \\
\hline$p$-value* & \multicolumn{2}{|c|}{$<0.001$} \\
\hline \multicolumn{3}{|c|}{ Bilirubin ( $\mu \mathrm{mol} / \mathrm{l})$} \\
\hline Median & 1.8 & 2.8 \\
\hline IQR & $1.6-1.9$ & $2.5-2.9$ \\
\hline Mean rank & 7.08 & 20.08 \\
\hline$p$-value* & \multicolumn{2}{|c|}{$<0.001$} \\
\hline
\end{tabular}

- Hepatic regeneration ratio $=$ liver weight per $100 \mathrm{~g}$ body weight at sacrification/preoperative projected liver weight ${ }^{*}$ per $100 \mathrm{~g}$ body weight ("Preoperative projected liver weight: Weight of resected liver at hepatectomy/0.7);

- Net regeneration $=$ liver weight at sacrification/preoperative projected liver weight/resected liver weight.

\section{Determination of DNA fragmentation by flow cytometry}

The liver samples from different groups were thawed and minced with a scalpel in a cold PBS solution, incubated for $15 \mathrm{~min}$ at $4^{\circ} \mathrm{C}$. The samples were filtered through a nylon mesh. After washing in the PBS solution and centrifugation, the cells chosen for analysis were collected and incubated with a solution containing propidium iodide (PI) $(10 \mu \mathrm{g} / \mathrm{ml}$, Sigma) and RNase ( $1 \mathrm{mg} / \mathrm{ml}$, Sigma). The tubes were placed at $4^{\circ} \mathrm{C}$ in the dark for at least $30 \mathrm{~min}$ before analysis by flow cytometry. The PI fluorescence of individual nuclei was measured using Coulter Epics XL. At least $5 \times 10^{3}$ cells of each sample were measured. Apoptotic and stained cells were represented by a subdiploid peak of cells that can be easily discriminated from the peak of cells with the diploid DNA content in the red fluorescence channel, analyzed by six-color flow cytometry on a FACS Canto II (BD Biosciences) with Flow Jo software (Tree Star, Inc., Ashland, OR). The percentage of apoptosis was indicated by the percentage of cells with subdiploid DNA content [27].

\section{Statistical analysis}

The Shapiro-Wilk $(p<0.001)$ non-parametric statistical test was used for comparisons of groups. The Mann-Whitney $U$-test was applied to compare two groups whereas the Kruskal-Wallis test was applied to compare more than two groups. Student's $t$-test was applied to compare means of two groups for normally distributed variables. The statistical significance level was determined at 0.05 .

\section{Results}

The levels of ALT, AST and ALP were significantly highest in the untreated group of rats with liver resection (median values were 244.15, 118.3 and $185 \mathrm{IU} / \mathrm{l}$, respectively), followed by the group with resection and treatment (median values were 180.7, 68.8 and 113 IU/l, respectively with $p<0.001$ ). Regarding bilirubin level, the highest value was observed in the resected group with treatment (median was $2.8 \mu \mathrm{mol} / \mathrm{l}$ ), followed by 
$1.8 \mu \mathrm{mol} / \mathrm{l}$ in the group with liver resection, $p<0.001$ (Table 1).

From Table 2, it is evident that the rat weight at sacrification was significantly lower in the group of rats treated with IL- 6 than those without treatment (median values were 217 and 232.5 gm, respectively), $p<0.001$. On the other hand, liver weight at sacrification was significantly higher in the group of rats treated with IL-6 (median values were 3.10 and 2.23 gm, respectively, $p<0.001$. There were no statistically significant differences in rat weight at baseline, weight of $70 \%$ resected liver, total liver weight and rest of liver weight between group of rats treated with IL-6 and those not treated (Table 2).

Since the distribution of liver enzymes and regeneration rate were abnormal as evidenced by the significant Shapiro-Wilk test $(p<0.001)$, non-parametric statistical tests were used for comparisons of groups. The Mann-Whitney $U$-test was applied to compare the two groups. For normally distributed variables, Student's $t$-test was applied to compare means of two groups.

\section{Flow cytometry for liver cell apoptosis}

The percentage of apoptotic cells with hypodiploid DNA content was determined from DNA histograms. Untreated rat resected liver showed a peak pattern which represented liver damage with high damage of

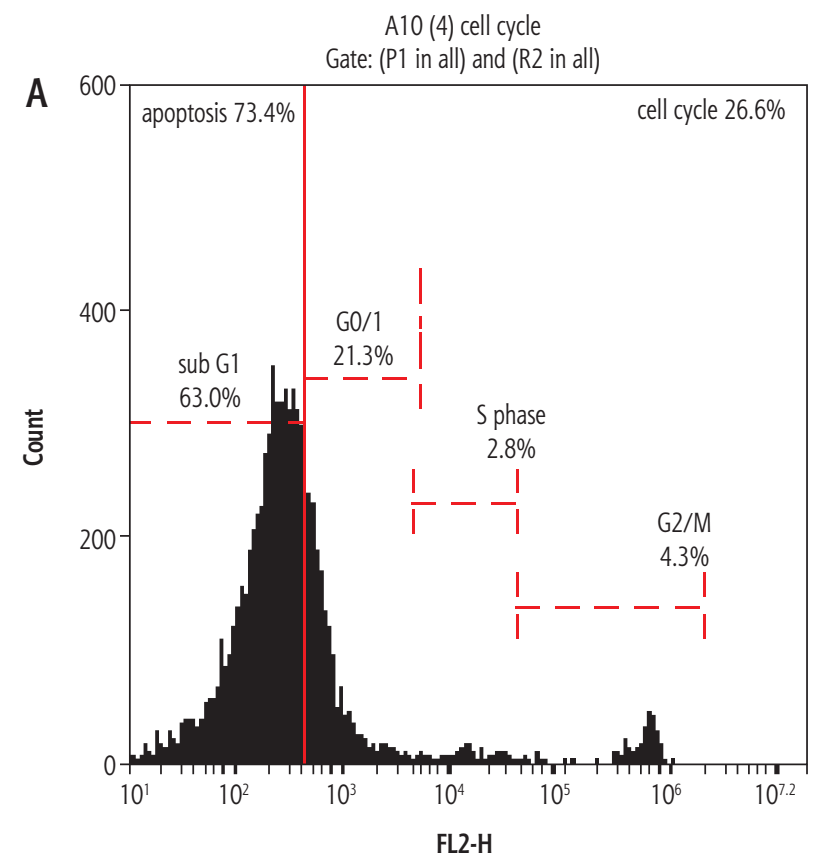

Table 2. Impact of IL-6 therapy on rats' and liver weights

\begin{tabular}{|c|c|c|}
\hline & \multicolumn{2}{|c|}{ IL-6 therapy } \\
\hline & $\begin{array}{c}\text { Without } \\
n=40\end{array}$ & $\begin{array}{c}\text { With } \\
n=40\end{array}$ \\
\hline \multicolumn{3}{|l|}{ Rat weight at baseline (gm) } \\
\hline Mean \pm SD & $239.55 \pm 4.49$ & $241 \pm 4.33$ \\
\hline$p$-value* & \multicolumn{2}{|c|}{0.305} \\
\hline \multicolumn{3}{|l|}{ Rat weight at sacrification } \\
\hline Median & 232.5 & 217 \\
\hline IQR & $226-238.5$ & $212.3-219$ \\
\hline Mean rank & 29.60 & 11.4 \\
\hline$p$-value** & \multicolumn{2}{|c|}{$<0.001$} \\
\hline \multicolumn{3}{|l|}{ Liver weight at sacrification } \\
\hline Median & 2.23 & 3.10 \\
\hline $\mathrm{IQR}$ & $2.13-2.35$ & 29.95-3.22 \\
\hline Mean rank & 11.5 & 29.5 \\
\hline$p$-value** & \multicolumn{2}{|c|}{$<0.001$} \\
\hline Weight of $70 \%$ resected liver (gm) & $4.94 \pm 0.37$ & $4.86 \pm 0.3$ \\
\hline$p$-value* & \multicolumn{2}{|c|}{0.490} \\
\hline Total liver weight (gm) & $7.07 \pm 0.4$ & $9.91 \pm 0.41$ \\
\hline$p$-value* & \multicolumn{2}{|c|}{0.228} \\
\hline Rest of liver weight (gm) & $2.15 \pm 0.16$ & $2.07 \pm 0.12$ \\
\hline$p$-value* & \multicolumn{2}{|c|}{0.071} \\
\hline
\end{tabular}

IQR - inter-quartile range, SD - standard deviation, *Student't-test, * * Mann-Whitney U-test

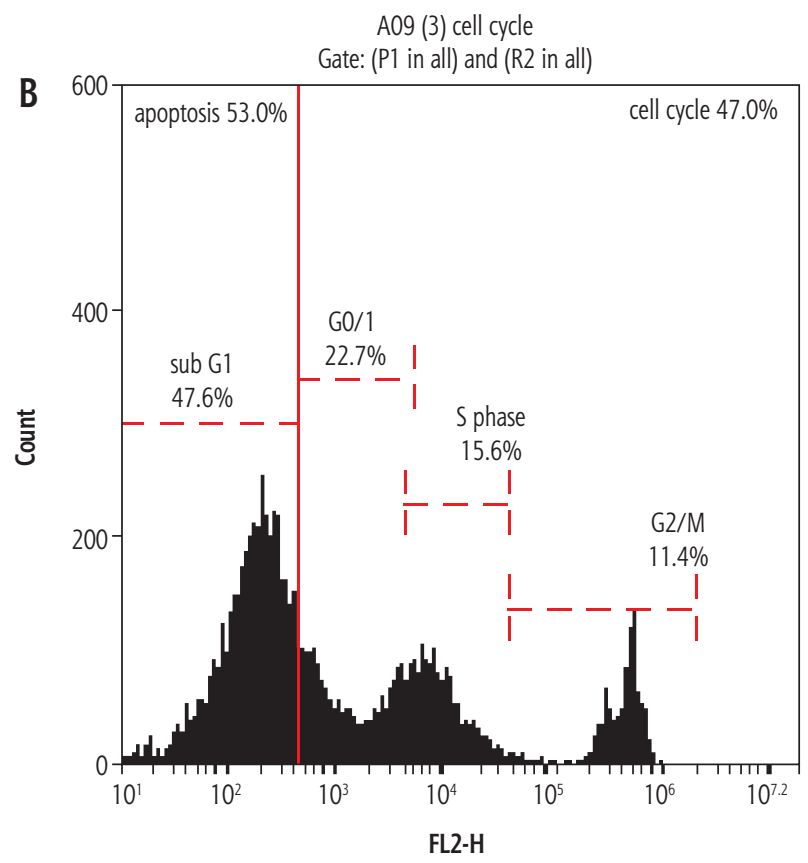

Fig. 1. Histogram showing apoptosis. The value in the liver cell damage which is represented by apoptosis as seen in the histogram was higher in the resected untreated liver rats group, $73.4 \%$, as seen in (A), which showed marked decline in the apoptotic percent to be $53 \%$ in the treated group that received IL-6 treatment as illustrated in (B). A, B) The apoptosis is identified by its dark black-area staining using propidium iodide staining solution to stain DNA (PI stain), which denotes marked DNA fragmentation 
73.4\% (Fig. 1A). However, the rats which had their liver treated with IL- 6 at $(35 \mu \mathrm{g} / 100$ gm body weight according to the lethality study) showed alteration and relative size reduction of the peak. Moreover, a significant parallel shift to less-intense fluorescence was induced. This decrease in the intensity and shift may be termed nuclear apoptosis and fragmentation reduction (Fig. 1B).

\section{Discussion}

In the present study, seventy percent of liver mass was resected. Furchtgott et al. [27] reported the significant features for the regenerative process following a two thirds partial hepatectomy. Panis et al. [28] stated that partial hepatectomy more than $75 \%$ would result in liver insufficiency; between $40 \%$ and $70 \%$ would have a quite rapid regenerative response, with a distinct peak in the proliferative activity as evident from the study of Bucher and Swaffield [29]. Partial hepatectomy less than $40 \%$ has a much slower response, with a low, quite constant proliferative activity during the response [30] resulting in impaired regenerative growth [30]. Lastly, for partial hepatectomy less than $10 \%$, a very minute regenerative response was noted. This coincides with the report of MacDonald et al. [31], who described a threshold quantity of liver; at least $9-12 \%$ of liver mass must be removed to evoke a significant response for DNA synthesis. Synthesis of DNA occurs at different times in liver parenchymal and nonparenchymal cells [32].

On the other hand, several reports have indicated that $90 \%$ hepatectomy is mostly fatal [33]. The reason(s) for this is not obvious. It is highly likely that the failure to regenerate after $90 \%$ hepatectomy in rodents is attributable to portal vein pressure impacting on hepatic artery flow, though other factors related to gene expression, growth factors, and cytokines have not been entirely ruled out as contributors to this phenomenon. The ECM is produced by nonparenchymal cells, whereas the metabolic load is relieved by the growth of parenchymal cells $[34,35]$.

The levels of ALT, AST and ALP were significantly highest in the group of rats with liver resection (median values were $244.15,118.3$ and $185 \mathrm{IU} / \mathrm{l}$, respectively), followed by the group with resection and treatment (median values were 180.7, 68.8 and 113 IU/l, with $p<0.001$. The explanation of elevation of liver enzymes in the non-treated group is due to that ALT and AST; enzymes involved in amino acid metabolism levels are related to the liver parenchymal cells and are increased if liver parenchymal cells are modified or damaged with increase in their blood concentration. In treated cases, the rate of damaged hepatocytes is decreased, so liver enzymes will be decreased in a range lower than in the non-treated group [36-42].

This coincides with the study of Kim et al. [40], who reported that the liver function change was evaluated according to the liver regeneration rate. The study showed that ALT, AST, TB and ALP levels rapidly increased at 7 days after surgery compared to the state before surgery and then decreased at 16 months after surgery, recovering compared to the state before surgery. Also, Kim et al. [40] found that the rapid increase at 7 days after surgery is considered to be triggered by liver parenchymal cells' modification and increased enzyme activity. In addition, liver cells are recovered as time goes on so that ALT and AST are considered to be decreased. Also elevated ALT and bilirubin levels two days after hepatectomy was compatible with the study of Haldrup et al. [26], who studied liver enzymes after partial hepatectomy in high fat cholesterol groups compared with standard diet animals. Also, it coincides with many previous studies.

Regarding bilirubin level, a higher value was observed in the treated group $(2.8 \mu \mathrm{mol} / \mathrm{l})$ than the untreated group $(1.8 \mu \mathrm{mol} / \mathrm{l})$ with $p<0.001$. This coincides with the observation by Kim, who revealed that any alteration in liver cells will give rise to bilirubin level [40]. The elevation of bilirubin as well as liver enzymes are in line with many studies, such as the study of Yang et al. [42], Deqli Esposti et al. [43], and Lei et al. [44], who observed these elevations in liver enzymes postoperatively and reported a positive correlation with the liver enzymes and IL-6 therapy [45-48].

Several cytokines and growth factors, including epidermal growth factor, hepatocyte growth factor, IL-6, TGF- $\alpha$ and TNF- $\alpha$, were found to play a role in the process of hepatocyte regeneration [11]. Rats deficient in these diverse proteins thus display severe abnormalities in either liver development or regeneration [45].

In the present study, it is evident that the rat weight at sacrification was significantly lower in the group of rats treated with IL-6 than those without treatment. On the other hand, liver weight at sacrification was significantly higher in the group of rats treated with IL-6. In both cases the $p$-value is highly significant. The weight of rats is decreased in the treated group at sacrification owing to generalized weight loss due to the increased metabolic process with energy loss induced by growth factors and cytokines that have been elevated by the effect of treatment with IL-6 [11-15]. The marked proliferative rate of hepatocytes induced by growth factors, mainly hepatocyte growth factor and IL-6, will give rise to increase cell mass and hence the liver weight in the treated group is higher than in the non treated group [18-22]. 
In the present study, the percentage of apoptotic cells with hypodiploid DNA content in the untreated resected liver showed a peak pattern which represented liver damage with high damage of $73.4 \%$. However, the rats which had their liver treated with IL- 6 showed alteration and relative size reduction of the peak. This coincides with data obtained by many previous studies using flow cytometric studies in liver cell regeneration [46-49].

\section{Conclusions}

Liver enzymes showed improvement after IL-6 administration in addition to less breakdown of DNA, which denotes a marked improvement in apoptotic rate in the treated group using IL-6 therapy, which is evident in the histogram of the flow cytometric study. Furthermore, liver cell mass was increased in the treated group, which indicates the potential of IL- 6 in the induction of liver cell regeneration. Thus, IL- 6 has triple functions in the regenerated liver: improving the liver enzymes, reducing apoptosis and increasing the rate of liver cell regeneration.

\section{Disclosure}

The research is funded by Albaha University, Saudi Arabia.

The authors report no conflict of interest.

\section{References}

1. Fausto N, Riehle KJ. Mechanisms of liver regeneration and their clinical implications. J Hepatobiliary Pancreat Surg 2005; 12: 181-189.

2. Mangnall D, Bird NC, Majeed AW. The molecular physiology of liver regeneration following partial hepatectomy. Liver Int 2003; 23: $124-138$.

3. Heath JK. Principles of cell proliferation. Blackwell Science, Oxford, UK 2000.

4. Su AI, Guidotti LG, Pezacki JP, et al. Gene expression during the priming phase of liver regeneration after partial hepatectomy in mice. Proc Natl Acad Sci USA 2002; 99: 11181-11186.

5. Taub R. Liver regeneration: from myth to mechanism. Nat Rev Mol Cell Biol 2004; 5: 836-847.

6. Fausto N, Campbell JS, Riehle KJ. Liver regeneration. Hepatology 2006; 43: S45-S53.

7. Iwai M, Cui TX, Kitamura H, et al. Increased secretion of tumor necrosis factor and interleukin 6 from isolated, perfused liver of rats after partial hepatectomy. Cytokine 2001; 13: 60-64.

8. Levy DE, Darnell JE. STATs: transcriptional control and biological impact. Nat Rev Mol Cell Biol 2002; 3: 651-662.

9. Mohammed FF, Khokha R. Thinking outside the cell: proteases regulate hepatocyte division. Trends Cell Biol 2005; 15: 555-563.

10. Serandour A, Loyer P, Garnier D, et al. TNF- $\alpha$-mediated extracellular matrix remodeling is required for multiple division cycles in rat hepatocytes. Hepatology 2005; 41: 478-486.

11. Michalopoulos GK. Liver regeneration. J Cell Physiol 2007; 213: 286-300
12. Blindenbacher $A$, Wang $X$, Langer I, et al. Interleukin 6 is important for survival after partial hepatectomy in mice. Hepatology 2003; 38: 674-682.

13. Ren X, Hogaboam C, Carpenter A, et al. Stem cell factor restores hepatocyte proliferation in IL-6 knockout mice following 70\% hepatectomy. J Clin Invest 2003; 112: 1407-1418.

14. Gallucci RM, Simeonova PP, Toriumi W, et al. TNF-alpha regulates transforming growth factor-alpha expression in regenerating murine liver and isolated hepatocytes. J Immunol 2000; 164: 872-878.

15. Ren X, Hu B, Colletti L. Stem cell factor and its receptor, c-kit, are important for hepatocyte proliferation in wild-type and tumor necrosis factor receptor-1 knockout mice after 70\% hepatectomy. Surgery 2008; 143: 790-802.

16. Brand S, Dambacher J, Beigel F, et al. IL-22 mediated liver cell regeneration is abrogated by SOCS-1/3 overexpression in vitro. Am J Physiol Gastrointest Liver Physiol 2007; 292: 1019-1028.

17. Zenewicz LA, Yancopoulos GD, Valenzuela DM, et al. Interleukin-22 but not interleukin-17 provides protection to hepatocytes during acute liver inflammation. Immunity 2007; 27: 647-659.

18. Moh A, Iwamoto Y, Chai GX, et al. Role of Stat-3 in liver regeneration: survival, DNA synthesis, inflammatory reaction and liver mass recovery. Lab Invest 2007; 87: 1018-1028.

19. Zimmers TA, McKillop IH, Pierce RH, et al. Massive liver growth in mice induced by systemic interleukin 6 administration. Hepatology 2003; 38: 326-334.

20. Akhurst B, Matthews V, Husk K, et al. Differential lymphotoxin-beta and interferon gamma signaling during mouse liver regeneration induced by chronic and acute injury. Hepatology 2005; 41: 327-335.

21. Kawamura H, Govindarajan S, Aswad F, et al. HCV core expression in hepatocytes protects against autoimmune liver injury and promotes liver regeneration in mice. Hepatology 2006; 44: 936-944.

22. Ren X, Carpenter A, Hogaboam C, et al. Mitogenic properties of endogenous and pharmacological doses of macrophage inflammatory protein- 2 after $70 \%$ hepatectomy in the mouse. Am J Pathol 2003; 163: 563-570.

23. Sanchez A, Nagy P, Thorgeirsson SS. STAT-3 activity in chemically-induced hepatocellular carcinoma. Eur J Cancer 2003; 39: 2093-2098.

24. Higgins GM, Anderson RM. Experimental pathology of the liver. Arch Pathol 1931; 12: 186-192.

25. Dasyukevich O, Solyanik G. Comparative study of anticancer efficacy of aonitine-containing agent bcl against ascite and solid forms of Ehrlich's carcinoma. Exp Oncol 2007; 29: 317-319.

26. Haldrup D, Heebøll S, Thomsen KL, et al. Preserved liver regeneration capacity after partial hepatectomy in rats with non-alcoholic steatohepatitis. World J Hepatol 2018; 10: 8-21.

27. Furchtgott LA, Chow CC, Periwal V. A model of liver regeneration. Biophys J 2009; 20: 3926-3935.

28. Panis Y, McMullan DM, Emond JC. Progressive necrosis after hepatectomy and the pathophysiology of liver failure after massive resection. Surgery 1997; 121: 142-149.

29. Bucher NL, Swaffield MN. The rate of incorporation of labeled thymidine into the deoxyribonucleic acid of regenerating rat liver in relation to the amount of liver excised. Cancer Res 1964; 24: 1611-1625.

30. Mitchell C, Nivison M, Jackson LF, et al. Heparin-binding epidermal growth factor-like growth factor links hepatocyte priming with cell cycle progression during liver regeneration. J Biol Chem 2005; 280: 2562-2568. 
31. MacDonald RA, Rogers AE, Pechet G. Regeneration of the liver: relation of regenerative response to size of partial hepatectomy. Lab Invest 1962; 11: 544-548.

32. Taub R. Liver regeneration: from myth to mechanism. Nat Rev Mol Cell Biol 2004; 5: 836-847.

33. Makino H, Togo S, Kubota T, et al. A good model of hepatic failure after excessive hepatectomy in mice. J Surg Res 2005; 127: 171-176.

34. Demetris AJ, Kelly DM, Eghtesad B, et al. Pathophysiologic observations and histopathologic recognition of the portal hyperperfusion or small-for-size syndrome. Am J Surg Pathol 2006; 30: 986-993.

35. Smyrniotis V, Kostopanagiotou G, Kondi A, et al. Hemodynamic interaction between portal vein and hepatic artery flow in small-for-size split liver transplantation. Transpl Int 2002; 15 : 355-360.

36. Lautt WW. Mechanism and role of intrinsic regulation of hepatic arterial blood flow: Hepatic arterial buffer response. Am J Physiol 1985; 249: 549-556.

37. Kelly DM, Demetris AJ, Fung JJ, et al. Porcine partial liver transplantation: A novel model of the "small-for-size" liver graft. Liver Transpl 2004; 10: 253-263.

38. Violi F, Ferro D, Basili S, et al. Prognostic value of clotting and fibrinolytic systems in a follow-up of 165 liver cirrhotic patients CALC Group. Hepatology 1995; 22: 96-100.

39. Mitchell JR, Nelson SD, Thorgeirsson SS, et al. Metabolic activation: biochemical basis $\mathrm{N}$ for many drug-induced liver injuries. Prog Liver Dis 1976; 5: 259-279.

40. Kim MS, Lee HK, Kim SY, et al. Analysis of the relationship between liver regeneration rate and blood levels. Pak J Med Sci 2015; 31: 31-36.

41. Vella SJ, Beattie P, Cademartiri R, et al. Measuring markers of liver function using a micro patterned paper device designed for blood from a fingerstick. Anal Chem 2012; 84: 2883-2891.

42. Yang MK, Gwak MS, Seo SW, et al. Analysis of postoperative liver function and complications versus donor hepatectomy type for living-related liver transplantation. Korean J Anesthesiol 2004; 46: 72-77.

43. Deqli Esposti D, Sebagh M, Pham P, et al. Ischemic preconditioning induces autophagy and limits necrosis in human recipients of fatty liver grafts, decreasing the incidence of rejection episodes. Cell Death Dis 2011; 13: e111.

44. Lei J, Yan L, Wang W. Donor safety in living donor liver transplantation: a single-center analysis of 300 cases. PLoS One 2013; 8: e 61679.

45. Smith AJ, Oude Elferink RP. Liver gene disruptions: winners by KO? J Hepatol 1999; 31: 752-759.

46. Tamura J, Tanaka J, Fujita K, et al. Cell kinetics of regenerating liver after $70 \%$ hepatectomy in rats - 2-color flow cytometric analysis. HPB Surg 1992; 5: 103-104.

47. Minamishima YA, Nakayama K, Nakayama K. Recovery of liver mass without proliferation of hepatocytes after partial hepatectomy in Skp2-deficient mice. Cancer Res 2002; 15: 995-999.

48. Tanaka M, Miyajima A. Identification and isolation of adult liver stem/progenitor cells. Methods Mol Biol 2012; 826: 25-32.

49. Suzuki A, Sekiya S, Onishi M, et al. Flow cytometric isolation and clonal identification of self-renewing bipotent hepatic progenitor cells in adult mouse liver. Hepatology 2008; 48: 1964 1978 